\title{
AGRICULTURA FAMILIAR E POLÍTICAS PÚBLICAS
}

\author{
Nilce Panzutti ${ }^{1}$ \\ Ana Victoria Monteiro ${ }^{2}$
}

\begin{abstract}
Resumo: O presente artigo tem como objetivo primeiro apresentar políticas públicas direcionadas e aplicadas ao segmento da denominada agricultura familiar, que nas últimas décadas vem se consolidando com o apoio de políticas específicas, como as que se referem às compras institucionais, e contando com diversos instrumentos para o seu desenvolvimento, no sentido de gerar empregos, distribuir renda e contribuir para o desenvolvimento local. Em segundo lugar, esboça a integração existente entre os programas e a rede formada pelas instituições que participam da implementação dessas políticas. Para a realização deste trabalho procedeu-se a: a) levantamento de publicações e de documentos digitais, seleção e leitura de material sobre a agricultura familiar e das políticas públicas para o meio rural; b) consulta a sites oficiais, como o do Ministério do Desenvolvimento Agrário (MDA), Ministério do Desenvolvimento Social e Combate à Fome, entre outros, e c) sistematização e análise baseadas em reflexões sobre dados obtidos. A importância estratégica da agricultura familiar, além de seu fundamental papel social na mitigação do êxodo rural e na desigualdade social do campo e das cidades, deve ser encarada pela sua capacidade de geração de riqueza, não apenas para o setor agropecuário, mas para a própria economia do país.
\end{abstract}

Palavras-Chave: Agricultura Familiar, Políticas Públicas, PRONAF, PNAE, PAA.

Abstract: This article aims firstly to present public policies directed and applied to segment of the so-called family farming, which over the last few decades has been consolidating itself with the support of specific policies, such as those related to institutional purchases, and of several instruments for its development in order to generate jobs, income distribution and local development. Secondly, it outlines the existing integration between the programs and the network formed by the institutions participating in policy implementation. To this end, three steps were taken: a) a survey of printed and digital publications and documents, followed by the selection and reading of the literature on family farming and public policies for rural areas; b) visits to the official websites, such as the Ministry of Agrarian Development (MDA), Ministry of Social Development and Fight Against Hunger, among others c) systematization and analysis arising from reflections on the data acquires. The strategic importance of family farming, besides its key social role in mitigating rural exodus and social inequality both in the countryside and cities, should be seen in its ability to generate wealth, not only for the agricultural sector, but for the country's economy as a whole.

Keywords: Family Farming, Public Policies, PRONAF, PNAE, PAA.

\footnotetext{
Doutora em Ciências Sociais pela UNICAMP, Pesquisadora Científica do Instituto de Economia Agrícola-IEA

2 Mestre em Geografia pela UNESP, Pesquisadora Científica do Instituto de Economia Agrícola -IEA
} 


\section{INTRODUÇÃO}

A questão agrária no Brasil contemporâneo apresenta novas faces na luta por terra, com a emergência de novos personagens, novas identidades e crescente valorização política da agricultura familiar.

Inúmeros estudos nacionais e internacionais tem demonstrado a importância da agricultura familiar para o desenvolvimento sustentável e que a agricultura familiar é capaz de gerar empregos, distribuir renda, contribuindo para o desenvolvimento local. Outra característica apontada a favor, é a sua contribuição para a diversificação do uso do espaço rural, praticando a exploração agrícola com preservação do meio ambiente. Seu desenvolvimento promove a criação de externalidades positivas, quais sejam: garantia de maiores fontes de biodiversidade, melhoria da segurança alimentar; preservação das características paisagísticas do território e do capital cultural das populações, fortalecimento das relações familiares e com isto diminuição do êxodo rural.

No Brasil, a agricultura familiar sempre foi um setor marginalizado devido á herança colonial e ao processo de "modernização" desigual da agricultura, onde os grandes e médios produtores patronais ligados ao setor exportador, principalmente das regiões Sul e Sudeste e, recentemente da região Centro Oeste, foram os principais beneficiários dos estímulos governamentais para o meio rural.

Mesmo sob adversidades como insuficiência de terras e capital, dificuldades no financiamento, baixa disponibilidade tecnológica e fragilidade da assistência técnica, o peso da agricultura familiar na riqueza do País é representativo e não perdeu sua importância nos últimos anos.

Somente, mais recentemente, de 1995 para cá, as políticas públicas para agricultura familiar ampliaram a participação do setor no PIB brasileiro, assegurando mercado, renda e emprego para esse segmento (Tabela 1). A agricultura familiar no Brasil representa $85,2 \%$ do total dos estabelecimentos rurais, ocupando apenas $30.5 \%$ da área da área total é responsável por $37,9 \%$ do valor bruto da produção agropecuária nacional e por 77\% da ocupação de mão-de-obra no campo, dados do Censo Agropecuário 1995/1996-IBGE (FAO/INCRA, 2001). Segundo a classificação dos estabelecimentos do Censo Agropecuário, 2006, proposta por KAGEYAMA et alii ( 2014), no Estado de São Paulo 66,8\% dos estabelecimentos são formados por assentados e exclusivamente familiares e $17 \%$ são familiares com contratação de mão de obra $(83,8 \%)$. 
Tradicionalmente, a agricultura de base patronal sempre foi considerada como vetor do desenvolvimento rural no Brasil. Os agricultores familiares começaram a entrar na pauta do governo somente após a reforma da Assembleia Nacional Constituinte, em 1987. Em virtude do contexto macroeconômico da reforma do Estado, a partir da década de 90 surgiram as políticas públicas destinadas a esse segmento motivadas pela crescente necessidade de intervenção estatal face à crescente exclusão social e o fortalecimento dos movimentos sociais rurais.

Assim, em 1995 é lançada uma linha de crédito de custeio diferenciada para financiar a agricultura familiar através do Programa Nacional de Fortalecimento da Agricultura Familiar (PRONAF) que logo em seguida passa a adquirir o "status" de programa governamental, com maior abrangência e nova concepção.

O presente artigo tem o objetivo de apresentar políticas públicas direcionadas e aplicadas ao segmento da denominada agricultura familiar, que nas ultimas décadas vem se consolidando, com o apoio de políticas específicas, como as que se referem às compras institucionais e contando com diversos instrumentos para o seu desenvolvimento no sentido de gerar empregos, distribuir renda e contribuir para o desenvolvimento local. Em segundo lugar, esboçar a integração existente entre os programas e a rede formada pelas instituições que participam da implementação das políticas.

\section{PROCEDIMENTOS METODOLÓGICOS}

Para a realização deste trabalho procedeu-se da seguinte forma: a) levantamento de publicações e documentos digitais, seleção e leitura de material sobre a agricultura familiar e políticas públicas para o meio rural; b) consulta à sites oficiais como o do Ministério do Desenvolvimento Agrário (MDA), Ministério do Desenvolvimento Social e Combate à Fome, c) Núcleo de Estudos Agrários e Desenvolvimento Agrário Rural (NEAD) , entre outros c) sistematização baseada em reflexões sobre dados colhidos. Neste trabalho, a categoria agricultura familiar é considerada para fins da política publica. No entanto, há que se levar em conta os desdobramentos da assumida diferenciação dos agricultores familiares considerando-os como são na realidade,-: diferentes entre si, não redutíveis a uma única categoria, a que utiliza predominantemente o trabalho familiar. As especificidades devem ser contempladas_tanto quanto são os contextos econômicos nos quais se inserem. Considerando que os programas e as ações das políticas direcionadas ao segmento estão vinculadas à essa heterogeneidade e que 
dependem das demandas e características as ações e o programa, há que haver a "harmonização" desse universo heterogêneo com os programas gerais.

PROGRAMA NACIONAL DE FORTALECIMENTO DA AGRICULTURA FAMILIAR - PRONAF

O PRONAF, instituído em meados de 1996, destina-se ao financiamento de custeio e investimento para o segmento dos pequenos produtores que utilizam mão de obra familiar, com o objetivo de propiciar condições para a produção, acesso à tecnologia, aquisição de equipamentos, insumos químicos e matrizes. Neste sentido, permite inserção de novos elementos, melhorando as condições desse segmento para a produção.

A missão principal do PRONAF é combater as desigualdades regionais, setoriais e pessoais que marcavam as políticas públicas tradicionais voltadas então para a mudança técnica da agricultura brasileira. O programa tinha três eixos: Pronaf Infra Estrutura, Pronaf Crédito e Pronaf Capacitação. Seguindo recomendação INCRA/FAO (1995) foram definidos três grupos diferenciados de agricultura familiar: consolidada (1,5 milhão de estabelecimentos); transição (2,5 milhão de estabelecimentos) e periférica (2,5 milhões de estabelecimentos).

Programa pressupunha em sua orientação e implementação um modelo de gestão descentralizada e participativa, através dos Conselhos $\mathrm{Mu}$ nicipais de Desenvolvimento Rural (CMDR), onde os agricultores familiares teriam participação majoritária garantida. Assim, constava no documento de criação do Programa que este deveria propiciar condições para o aumento da capacidade produtiva, a geração de empregos e a melhoria da renda, contribuindo para a melhoria da qualidade de vida e ampliação do exercício da cidadania por parte dos agricultores familiares. (MAA -Pronaf, 1996).

De acordo com a classificação do INCRA/FAO, o programa deveria privilegiar o segundo estrato: agricultura familiar de transição por serem agricultores com potencialidade de inserção no mercado. Pela linha de financiamento Pronaf Crédito seriam atendidos primordialmente os agricultores do segundo grupo transição enquanto o terceiro, agricultura familiar periférica na linha Pronaf Capacitação,visava habilitar tecnicamente os agricultores. O Pronaf Infra-estruturas e encarregaria de implantar, ampliar, modernizar as condições necessárias para dinamizar o setor, por meio de 
repasse de recursos para os municípios. Nesse conjunto, o primeiro grupo não teria necessidade de apoio, já que possuíam terra, tecnologia e crédito.

A legislação do PRONAF no que se refere à definição dos beneficiários mudou com o passar dos anos mudando também a definição dos beneficiários considerados como agricultores familiares. Desta forma, 15 grupos são contemplados pelo programa, com os seguintes requisitos: a) proprietários, assentados, posseiros, arrendatários, parceiros ou meeiros que utilizam mão de obra predominante familiar e tenham até 2 empregados permanentes; b) não detenham qualquer título e áreas superiores a 4 módulos fiscais; c) tenham renda bruta familiar com no mínimo $80 \%$ dela proveniente da agropecuária e não agropecuária desenvolvida no estabelecimento; d)residam na propriedade ou em local próximo ${ }^{3}$

Com os riscos dos produtores do segundo grupo - em transição, regredirem ao terceiro estado, de agricultores periféricos, e levando em consideração a existência ou não de potencialidade para serem promovidos para o modelo de agricultura familiar consolidada, mais a exigência de que um mínimo de $80 \%$ da renda bruta familiar anual deva vir da atividade agropecuária, observa-se a tendência do programa excluir os agricultores e as regiões mais pobres que não conseguem sobreviver unicamente da exploração agropecuária e que necessitam complementar a renda com outras fontes - aposentadorias e atividades não agrícolas. Desta forma, o programa se distancia de seus objetivos iniciais e acaba favorecendo a parcela mais estruturada da agricultura familiar do país que consegue acessar os empréstimos bancários e as regiões mais ricas em detrimento das localidades mais pobres. Nesse sentido coloca-se uma distorção de perspectiva do programa que se propunha a ter uma lógica diferente da lógica concentradora das políticas tradicionais.

O bom desempenho de todo empreendimento rural familiar depende, como em outros negócios, do acesso aos mercados que melhor remunerem seus esforços. A inserção de grande parte dos agricultores familiares aos mercados se dá com forte grau de incerteza, absorção dos riscos da produção e do mercado e, parcela significativa, tem dificuldades para se capitalizar, realizar investimentos e levar adiante algum projeto inovador. A agricultura familiar sofre com a falta de políticas públicas efetivas, de proteção contra as flutuações acentuadas dos mercados e as variações climáticas da natureza.

3 A atualização dos dados para 2014/2015; atualizações de ações e do programa podem ser

acompanhadas pelo sites: www.mda.gov.bre www.jusbrasilcom.br/tópicos/420380/notícias/atualizações 
As vantagens e desvantagens efetivas da agricultura familiar dependem de como esse segmento opera dentro das condições concretas impostas pela realidade na qual está inserida e consegue valorização de seus ativos e atributos e aproveitar as oportunidades potenciais que surgem.

Historicamente os agricultores familiares enfrentam problemas relacionados à falta de mercado para seus produtos. Por essa razão, algumas iniciativas foram tomadas no sentido de estabelecer uma ligação entre as instituições públicas e a agricultura familiar de forma a criar um mercado estável para a produção local e fornecer alimentos de boa qualidade para os beneficiários de programas de alimentação.

\section{PROGRAMA NACIONAL DE ALIMENTAÇÃO ESCOLAR -PNAE}

O Programa Nacional de Alimentação Escolar (PNAE), 1996, foi uma dessas iniciativas, através de publicação da Portaria no. 291 de 08.08.96 determinando, pela primeira vez, que as matérias primas e os alimentos produzidos e comercializados na região teriam prioridade, como forma de incentivar a produção local. Desta forma, seriam priorizadas nas aquisições as matérias primas e os alimentos, ${ }_{2}$ conforme a vocação agrícola e agroindustrial, com reflexos também no desenvolvimento local sustentável.

Visando a melhoria da qualidade nutricional das escolas e creches a preservação dos hábitos alimentares regionais e a garantia de aquisição da produção local de frutas, legumes e hortaliças, em 2004, na II Conferência Nacional de Segurança Alimentar e Nutricional define-se a compra direta dos agricultores familiares e produção agrícola local, para merenda escolar. Neste particular, apesar do apoio legal governamental, foram encontradas dificuldades entre o grau de exigência das licitações para compras e prestação de contas e o alto grau de informalidade dos agricultores familiares dos municípios, inviabilizando-os enquanto fornecedores.

No Encontro da Agricultura Familiar com a Alimentação Escolar (abril, 2012) estimou-se que 250 mil famílias agricultoras poderão ser beneficiadas e 47 milhões de alunos da educação básica da rede pública,através do Programa Nacional de Alimentação Escolar (PNAE). Lei. n.11.947/ 2009. http://www.mda.gov.br/alimentacaoescolar

As linhas mestras da Agricultura Familiar na perspectiva da produção e venda pressupõe o desenvolvimento agrário sustentável, geração de renda e agregação de valor, segurança alimentar, combate a pobreza rural. Do lado de quem compra a alimentação escolar, pressupõe-se o resp eito às tradições e hábitos alimentares saudáveis, educação alimentar, segurança 
alimentar.

Participam do PNAE os seguintes atores: CONSEA- Conselho Nacional de Segurança Alimentar; CONAB - Companhia Nacional de Abastecimento; ATER - Assistência Técnica e Extensão Rural (local); Organizações da Agricultura Familiar (SINTRAF- Sindicato da Agricultura Familiar, FETAESP - Federação dos Trabalhadores na Agricultura, FETRAF - Federação dos Trabalhadores na Agricultura Familiar, FAF - Federação da Agricultura Familiar); Agricultores Familiares, MDA -Ministério do Desenvolvimento Agrário; FNDE - Fundo Nacional de Desenvolvimento MDS - Ministério do Desenvolvimento Social e Combate à Fome; MAPA - Ministério da Agricultura, Pecuária e Abastecimento; ANVISA - Agência Nacional de Vigilância Sanitária; CMDRS - Conselhos Municipais de Desenvolvimento Rural; CAE Conselho de Alimentação Escolar; CONSED - Conselho Nacional de Secretários de Educação; Nutricionistas, Escolas, Prefeituras, Merendeiras, Estudantes e Universidades.

\section{PROGRAMA DE AQUISIÇÃO DE ALIMENTOS - PAA}

O Programa de Aquisição de Alimentos (PAA) foi uma das ações implementadas pelo Programa Fome Zero, criado pelo art. 19 de Lei 10.696 e regulamentado pelo Decreto 4.772, ambos de 02/07/2003. Tem como objetivo incentivar a agricultura familiar à produzir alimentos, direcionando os mesmos à pessoas em situação de insegurança alimentar (alimentação escolar, hospitais e outras entidades beneficentes) e à formação de estoques estratégicos. Visa contribuir para inclusão social e promover a cidadania.

Com o intuito de facilitar a implantação do programa - rapidez no escoamento, aplicação dos procedimentos legais, distribuição dos alimentos - o PAA autoriza a aquisição sem licitação de produtos da agricultura familiar através do mercado institucional. O limite é definido pelo Decreto que regulamenta o Programa, num valor máximo de produtos vendidos sem licitação $R \$ 3.500,00$, por agricultor familiar/ano.

Existe um Grupo Interministerial Gestor do Programa de Aquisição de Alimentos (Portaria Ministerial de 07.07.2003) para definir as medidas necessárias para a operacionalização do programa. Esse grupo é coordenado pelo Ministério do Desenvolvimento Social e Combate á Fome e composto por representantes dos seguintes Ministérios: Desenvolvimento Agrário, Desenvolvimento Social e Combate á Fome; Agricultura, Pecuária e Abastecimento; Planejamento, Orçamento e Gestão e Fazenda. 
De 2003 a 2005, o PAA foi operado exclusivamente com recursos disponibilizados no orçamento do Ministério de Desenvolvimento Social e desenvolvido através de parcerias entre a Secretaria de Segurança Alimentar e Nutricional - SESAN, governos estaduais e municipais, alem da CONAB. A partir de 2006 passou a ter uma maior participação do Ministério do Desenvolvimento Agrário, com dotação orçamentária própria.

Para a sua operacionalização o programa conta com diversos agentes federais, estaduais e municipais. Os gestores locais são as organizações compostas por agricultores familiares (cooperativas, associações, sindicatos dos trabalhadores rurais, etc.) e entidades da rede sócio assistencial. A CONAB foi delegada responsável para a aquisição e distribuição dos produtos por meio do Convênio CONAB-MESA n. 005/2003. Esta é responsável pela operacionalização do PAA nos Estados, garante a compra da produção e a determinação dos preços de mercado ao adquirir os alimentos ou sinalizar o preço de referência. No que se refere ao controle social, o acompanhamento do PAA esta a cargo da sociedade e suas representações de grupos já existentes: conselhos nacionais, estaduais e municipais relacionados à segurança alimentar e nutricional, desenvolvimento rural sustentável, etc.

Existe um critério básico de estratificação do universo familiar conforme Projeto de Cooperação Técnica INCRA/FAO (2000) para definir os tipos de agricultores familiares. Os parâmetros para discriminar os quatro tipos de agricultores familiares (A,B,C e D) são calculados considerando-se o Valor do Custo Oportunidade (VCO) como sendo o valor da diária média estadual para o trabalho, acrescido de $20 \%$ e multiplicado pelo número de dias úteis do ano (estimado em 260 dias), tendo em vista uma comparação com uma renda anual, isto é:

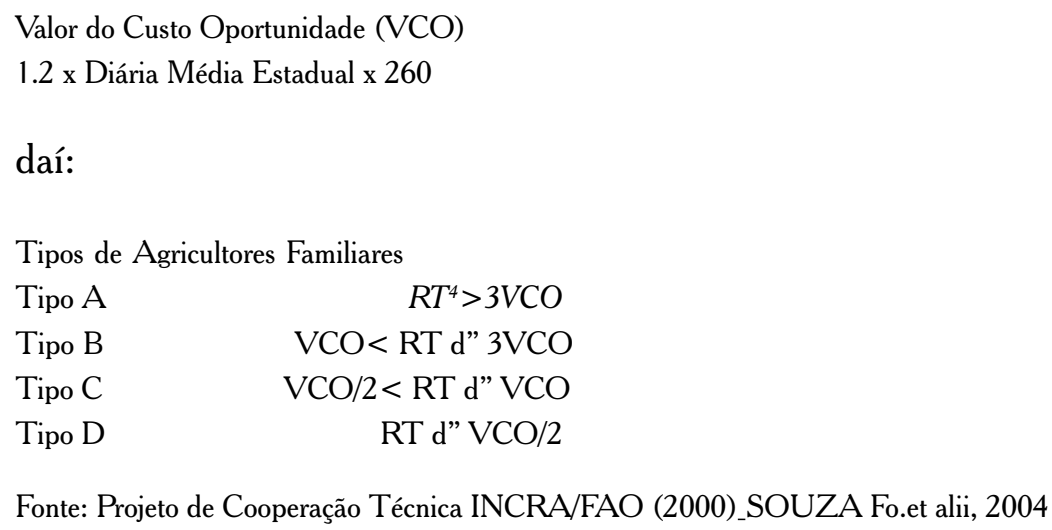


O PAA é direcionado para agricultores familiares enquadrados nos grupos $\mathrm{A}$ ao D do Programa Nacional de Fortalecimento da agricultura Familiar (PRONAF) e inclui: agricultores, pescadores artesanais. Silvicultores, extrativistas, indígenas, membros de comunidades remanescentes de quilombos e agricultores assentados pelos programas de acesso à terra.

Várias são as modalidades de operacionalização do PAA: a) Compra Direta da Agricultura Familiar (CDAF); b) Formação de Estoques pela Agricultura Familiar (CPR) c) Compra para Doação Simultânea ou Compra Direta Local (CDLAF) ou ainda Compra Antecipada Especial com Doação Simultânea (CAEAF).

\section{COMPRA DIRETA}

A modalidade Compra Direta da Agricultura Familiar permite a aquisição de alimentos para distribuição ou para formação de estoques públicos. Dessa forma, cumpre um importante papel na promoção da segurança alimentar e nutricional, na regulação de preços de alimentos e na movimentação de safras e estoques.

A operacionalização é de responsabilidade da Companhia Nacional de Abastecimento (Conab), de acordo com termo de cooperação firmado com o Ministério do Desenvolvimento Social e Combate à Fome (MDS). A modalidade permite a aquisição de produtos, à preços de referência, definidos pelo Grupo Gestor do Programa, até o limite de R\$ 8 mil por agricultor familiar/ano.

Para ser adquirido, o produto deve atender aos padrões de qualidade estabelecidos pelo Ministério da Agricultura, Pecuária e Abastecimento (Mapa). Depois pode ser entregue nas Unidades Armazenadoras da Conab ou em Pólos Fixos e Volantes de Compra.

Os alimentos adquiridos vão para os estoques da Conab e tem sido utilizados especialmente para compor as cestas de alimentos distribuídas a grupos populacionais específicos. Entre os produtos adquiridos pela modalidade, destacam-se o arroz, farinha de mandioca, feijão, milho, sorgro, trigo, leite em pó integral e farinha de trigo.

\section{COMPRA DIRETA LOCAL COM DOAÇÃO SIMULTÂNEA}

A modalidade Compra Direta Local com Doação Simultânea do PAA adquire produtos da agricultura familiar para abastecer os equipamentos públicos de alimentação e nutrição e também as ações de acesso à 
alimentação empreendidas por entidades da rede sócio assistencial local. A modalidade é desenvolvida pelo Ministério do Desenvolvimento Social e Combate à Fome (MDS) em parceria com governos de estados e municípios.

$\mathrm{Na}$ modalidade, o agricultor familiar comercializa diretamente alimentos de acordo com padrões de qualidade que são determinados pelos órgãos regionais competentes em um limite de $\mathrm{R} \$ 4,5$ mil por ano.

Os alimentos são entregues na Central de Distribuição da região, que irá destiná-los à Rede de Equipamentos Públicos de Alimentação e Nutrição, composta por Restaurantes Populares, Cozinhas Comunitárias e Bancos de Alimentos. Também são entregues à rede sócio assistencial, preferencialmente, indicada pelos Centros de Referência de Assistência Social (CRAS).

Para participar da modalidade Compra Direta Local com Doação Simultânea, os municípios devem ficar atentos aos editais públicos anuais disponíveis no site do MDS. Por meio da parceria com Estados, tem-se priorizado operações em municípios localizados em territórios da cidadania e territórios CONSAD nas regiões Norte e Nordeste do Brasil. Não está prevista a ampliação da modalidade para novos estados.

\section{FORMAÇÃO DE ESTOQUES}

A modalidade Formação de Estoques pela Agricultura Familiar foi criada para propiciar aos agricultores familiares, enquadrados no Programa Nacional de Fortalecimento da Agricultura Familiar (Pronaf), instrumentos de apoio à comercialização de seus produtos, sustentação de preços e agregação de valor. A operacionalização cabe à Companhia Nacional de Abastecimento (CONAB), a partir de acordo firmado com o Ministério do Desenvolvimento Social e Combate à Fome (MDS) e com o Ministério do Desenvolvimento Agrário (MDA).

A modalidade é importante para o MDS, pois propicia o fornecimento de alimentos básicos para distribuição a populações em situação de insegurança alimentar. Entre os alimentos adquiridos, destacam-se o arroz beneficiado, leite em pó, açúcar, farinha de milho e fubá.

Ao identificar a possibilidade de formação de estoque de determinado produto, a organização de agricultores envia uma Proposta de Participação à $\mathrm{CONAB}$ da região. A proposta deve conter o produto definido, o prazo para a formação do estoque, os preços e os agricultores a serem beneficiados. Com a aprovação, a organização emite a Cédula de Produto Rural (CPR-Estoque), e a Conab disponibiliza o recurso. 
A organização adquire a produção dos agricultores familiares listados na Proposta de Participação, beneficia os alimentos e os mantém em estoque próprio até sua entrega ou comercialização. $\mathrm{O}$ limite financeiro de participação por agricultor familiar é de $\mathrm{R} \$ 8$ mil por ano. Já o valor total da proposta de participação não pode ultrapassar $\mathrm{R} \$ 1,5$ milhão por cada organização/ano.

A CPR representa a promessa de entrega de determinado produto $\mathrm{e}$ tem um prazo de vencimento de, no máximo, 12 meses, devendo ser liquidada pela organização ao fim desse prazo. Com recursos do MDS, a liquidação deve ser em produtos, enquanto com recursos do MDA a quitação é realizada financeiramente pelo pagamento do valor recebido, acrescido de encargos de 3\% ao ano.

O Programa está presente em, aproximadamente, 3.000 municípios brasileiros. Foram adquiridos pelo Governo Federal 289.031 mil toneladas de alimentos, de 177.669 mil agricultores familiares, destinadas a um total de 15 mil entidades que atendem diretamente pessoas em situação de insegurança alimentar e nutricional, desde o início do programa. COSTA et alii (s/data).

Entre os produtos adquiridos estão: leite em pó, leite de cabra, queijo, farinha de mandioca, farinha de trigo, feijão, arroz, castanha do Brasil, castanha de caju, sementes, hortigranjeiros, sucos, polpas de frutas, doces, polpa de umbu, mel, açúcar mascavo, rapadura, frango, carne de bode, baru, salame e óleo de pequi_(COSTA et alii s/data ).

Estudos preliminares sobre os impactos do PAA indicam que foram positivos em diversas regiões, no que se refere ao aumento da renda monetária dos agricultores, melhoria na obtenção de maiores preços aos seus produtos, maior acesso a financiamentos com valores mais elevados. No entanto, apontam também haver um descompasso entre a liberação dos recursos para aquisição e a época da produção e no artigo que institui o PAA existe uma ambiguidade ao não separar as funções de " política agrícola" e de "política de segurança alimentar e nutricional" que o programa deveria cumprir integrando-as, sem misturá-las.

Indicam também que a agricultura familiar pode se integrar às cadeias agroindustriais mais dinâmicas existentes no País ou criar novos sistemas, entendendo que a melhor estratégia de desenvolvimento é preparar os agricultores familiares para competir de forma sustentável nos mercados globalizados, capacitá-los a aproveitar as oportunidades criadas nesses mercados, investir na potencialidade das vantagens e na redução das desvantagens competitivas próprias da agricultura familiar. 
De acordo com MULLER et alii (2012) a construção do PAA é resultado de uma sucessão de fases em que foi discutido o tema nos grupos institucionais e não institucionais através de rede inter=relacional formada pelos seguintes atores: membros de organizações de agricultores (sindicatos, federações, movimentos sociais); estudiosos e interessados no tema da agricultura familiar com participação em diversas organizações sociais, partidos políticos, universidades; atores de diversos órgãos governamentais . As relações entre os atores institucionais "reformistas" e a abertura de oportunidades às mudanças das forças políticas, abriram espaços para a formulação e execução das políticas voltadas a esse segmento da agricultura.

\section{CONSIDERAÇÕES FINAIS}

Motivado externamente pela globalização e, internamente pela crescente necessidade de intervenção estatal frente à crescente exclusão social e a forte demanda dos movimentos sociais rurais, na década de 1990, foram implantadas no País, medidas de política agrícola em prol da integração da agricultura familiar no contexto macroeconômico da reforma do Estado.

Esse segmento entra na pauta governamental com o desenvolvimento e implementação de programas com o intuito de proporcionar melhores rendimentos e condições de vida garantindo a comercialização da produção agrícola diversificada e promovendo a articulação dos agentes locais e com isto contribuindo para o desenvolvimento do segmento em escala regional (vide Tabela 1).

A agricultura familiar tem se tornado cada vez mais evidente no espaço rural, graças, em parte, ao apoio recebido em termos de políticas públicas. A continuidade desse apoio tenderá a viabilizar esse segmento como um dos mais aptos e capazes de abastecer mercados, de sustentar a biodiversidade e de prover necessidades elementares, como alimento e trabalho, para um número considerável de pessoas pelo interior do País.

Eventualmente, onde a concentração de unidades familiares de produção é maior, observa-se um comprometimento maior das políticas públicas como o Pronaf, no direcionamento majoritário dos recursos para produtores cujas rendas, em sua maior parcela, são originárias no estabelecimento, a exemplo dos grupos C e D. Essas unidades de produção constituem-se em unidades não unicamente agropecuárias, mas voltadas à outras atividades de diversificação e agregação de valor em setores vinculados ao meio como serviços e indústrias de transformação. Por isto, qualquer pro- 
posta de desenvolvimento sustentável para o campo ,necessariamente requer a desconcentração do processo produtivo e a dinamização da vida econômica, social e política do meio rural.

Muitas vezes o processo de modernização da produção beneficia mais a produção patronal que a familiar; a divergência entre tamanho, capital e tecnologia tornam diferenciadas as prioridades de cada produtor familiar. Isto dificulta uma organização comum a todos na busca dos próprios interesses. Enquanto em alguns locais existem associações e cooperativas, em outros essas organizações são inexistentes.

Por isto, dada a heterogeneidade da agricultura familiar, além das especificidades da produção se faz necessária uma caracterização e definição das regiões. Cultivos e criações, que dependem de mão-de-obra mais intensificada ou que estão situados em áreas que impossibilitem o uso da mecanização, devem ser considerados em programas de auxílio à produção familiar.

A importância estratégica da agricultura familiar, além de seu fundamental papel social na mitigação do êxodo rural e na desigualdade social do campo e das cidades, deve ser encarada pela sua capacidade de geração de riqueza, não apenas para o setor agropecuário, mas para a própria economia do país. 


\section{Tabela 1}

PIB DO AGRONEGÓCIO PATRONAL, FAMILIAR PERIODO 2002 A 2005BRASIL E ESTADO DE SÃO PAULO VALORES EM MIL REAIS DE 2005

\begin{tabular}{|c|c|c|c|c|}
\hline ANO & 2002 & 2003 & 2004 & 2005 \\
\hline PIB Total Nacional & 1.795 .776 .452 & 1.805.562.622 & 1.894.035.191 & \\
\hline PIB do Agronegócio & 518.332 .309 & 552.205 .294 & 566.311 .522 & 540.191 .535 \\
\hline Lavoura & 357.548 .420 & 385.058 .472 & 396.263 .951 & 373.367 .767 \\
\hline Pecuária & 160.783 .889 & 167.146 .823 & 170.047 .571 & 166.823 .768 \\
\hline PIB Total Nacional & 1.795.776.452 & 1.805.562.622 & 1.894.035.191 & \\
\hline PIB do Agronegócio Familiar & 166.099 .516 & 181.744 .936 & 181.890 .380 & 173.466 .315 \\
\hline Lavoura & 101.286 .113 & 113.814 .158 & 133.004 .297 & 103.535 .626 \\
\hline Pecuária & 64.813 .403 & 67.930 .778 & 68.886 .083 & 69.930 .689 \\
\hline PIB Total Nacional & 1.795 .776 .452 & 1.805.562.622 & 1.894.035.191 & \\
\hline PIB do Agronegócio Patronal & 352.232 .793 & 370.460 .395 & 384.421 .142 & 366.725 .220 \\
\hline Lavoura & 256.262 .307 & 371.244 .314 & 283.259 .654 & 269.832 .141 \\
\hline Pecuária & 95.970 .486 & 99.216 .045 & 101.161 .488 & 96.893 .079 \\
\hline PIB Total do Estado - São Paulo & 584.110 .187 & 547.108 .325 & 586.029 .781 & \\
\hline PIB do Agronegócio & 143.794 .438 & 147.661 .315 & 149.974 .461 & 146.029 .226 \\
\hline Lavoura & 112.007 .277 & 114.488 .015 & 116.407 .100 & 113.177.787 \\
\hline Pecuária & 31.787 .161 & 33.213 .300 & 33.576 .361 & 32.851 .439 \\
\hline PIB do Agronegócio Familiar & $26,959.140$ & & & \\
\hline Lavoura & 18.250 .285 & 28.226 .075 & 26.277 .177 & 26.785 .670 \\
\hline Pecuária & 8.708 .855 & $\begin{array}{r}18.888 .530 \\
9.337 .546\end{array}$ & $\begin{array}{r}18.233 .747 \\
8.043 .370\end{array}$ & $\begin{array}{r}17.947 .478 \\
8.811 .192\end{array}$ \\
\hline PIB do Agronegócio Patronal & 166.835 .298 & 119.435 .240 & 123.697.344 & 119.270 .556 \\
\hline Lavoura & 93.756 .992 & 95.559 .485 & 98.173 .353 & 95.230 .309 \\
\hline Pecuária & 23.078 .306 & 23.875 .754 & 25.523 .991 & 24.040 .247 \\
\hline
\end{tabular}

Fonte: NEAD Estudos; 19/IBGE; Brasília; MDA 2007 


\section{REFERÊNCIAS BIBLIOGRÁFICAS}

COSTA, J.P.; RIMKUS, L.M.; REYDON, B.P. Agricultura Familiar, Tentativas e Estratégias para assegurar um mercado e uma renda. Unicamp. 2008. Disponivel em: <http://www.sober.org.br/palestra/9/ 846.pdf>. Acesso em: 21 de março de 2012.

GUANZIROLI, C. E. (Coord.). Novo retrato da agricultura familiar: o Brasil redescoberto. Brasília, DF: FAO/INCRA, 2000. (Projeto de cooperação técnica INCRA/FAO). Disponível em: < http:// www.rlc.fao.org/proyecto/brazil/censo.pdf>. Acesso em: 01/07/2014

GUILHOTO, J.J.M.; ICHIHARA, S.M.; SILVEIRA, F.G.; AZZONI. Agricultura Familiar: contribuindo para a riqueza nacional. http://ideas.repec.org/p/pra/mprapa/31510.html. Acesso em 01/07/2014

INCRA/FAO Diretrizes de Política Agrária e Desenvolvimento Sustentável, Resumo do Relatório Final do Projeto URF/BRA/036, segunda versão. Brasília, 1995. Disponível em: http://www.rlc.fao.org/proyecto/ brazil/censo.pdfAcesso em 01/07/2014

KAGEYAMA, A. et alli Uma Classificação dos Estabelecimentos Agropecuários do Brasil, a partir do Censo Agropecuário de 2006. In: Aspectos Multidimensionais da Agricultura Brasileira: diferentes visões do Censo Agropecuário 2000. Schneider, S., Ferreira, B. Alves, F. - Brasília: Ipea, 2014, 387 p.

Ministério da Agricultura e Abastecimento MAA. PRONAF - Programa Nacional de Fortalecimento da Agricultura Familiar, Brasília, 1996

MULLER, A.L.; SILVA, M.K.; SCHNEIDER, S. A construção de políticas para a agricultura familiar no Brasil: Programa de Aquisição de Alimentos. Revista Estudos Sociedade e Agricultura (UFRJ). Rio de Janeiro, v. 20, p.139, 2012

PIB da Agricultura Familiar - Brasil-Estados/ Joaquim J.M. Guilhoto; Carlos R. Azzoni, Fernando Gaiger Silveira (et al.) Brasilia. NEAD/ MDA 2007.

SOUZA Fo. H. M.; BUANAIN, A.M.; GUANZIROLI, C.; BATALHA, M .O. Agricultura Familiar e Tecnologia no Brasil: características, desafios e obstáculos Disponível em http://www.sober.org.br/ palestra/12090442.pdf 